\title{
BMJ Open Associations between maternal age and socioeconomic status with smoking during the second and third trimesters of pregnancy: a register-based study of 932671 women in Finland from 2000 to 2015
}

Zahra Roustaei (D) , ${ }^{1}$ Sari Räisänen, ${ }^{2}$ Mika Gissler, ${ }^{3,4}$ Seppo Heinonen ${ }^{5}$

To cite: Roustaei Z, Räisänen S, Gissler M, et al. Associations between maternal age and socioeconomic status with smoking during the second and third trimesters of pregnancy: a register-based study of 932 671 women in Finland from 2000 to 2015. BMJ Open 2020;10:e034839. doi:10.1136/ bmjopen-2019-034839

- Prepublication history and additional material for this paper are available online. To view these files, please visit the journal online (http://dx.doi. org/10.1136/bmjopen-2019034839).

Received 07 October 2019 Revised 22 June 2020 Accepted 23 June 2020
Check for updates

(C) Author(s) (or their employer(s)) 2020. Re-use permitted under CC BY-NC. No commercial re-use. See rights and permissions. Published by BMJ.

For numbered affiliations see end of article.

Correspondence to Dr Zahra Roustaei; zahra.roustaei@helsinki.fi

\section{ABSTRACT}

Objectives This study aimed to explore the association between maternal age and smoking during the second and third trimesters of pregnancy across socioeconomic groups and to evaluate the interacting effect of maternal age and socioeconomic status on smoking with a view to informing public health interventions.

Design This is a register-based study.

Settings Data from the Finnish Medical Birth Register were cross-linked with background data from Statistics Finland.

Participants The information of 932671 pregnant women who gave birth in Finland from 2000 to 2015.

Main outcome measures Maternal smoking during the second and third trimesters of pregnancy by occupation and maternal age.

Results The proportion of women who smoked during the second and third trimesters of pregnancy was $10.5 \%$. Using women $30-34$ years as the reference group, adjusted ORs (aOR) and 95\% Cls for smoking were 6.02 (5.81 to 6.24) in women below 20 years and 2.77 (2.71 to 2.84 ) in women 20 to 24 years. The prevalence of smoking across socioeconomic groups compared with upper-level employees increased, peaking for women in manual occupations (aOR 3.39, $95 \% \mathrm{Cl} 3.25$ to 3.52 ) and unemployed women (aOR $4.49,95 \% \mathrm{Cl} 4.30$ to 4.68$)$. Significant interactions on the additive scale with the relative excess risk due to interaction $>2$ were found for unemployed women aged 25-29 years and for teenage mothers and mothers aged 20-24 years across all socioeconomic groups, but not for self-employed women.

Conclusions Smoking during the second and third trimesters of pregnancy was most common among teenage mothers across all socioeconomic groups. The association between maternal age and smoking differed by socioeconomic status for young mothers. Interventions should address a wider range of maternal risk factors among young mothers with low socioeconomic status and simultaneously target a broader number of women who smoke during the pregnancy.
Strengths and limitations of this study

- This study uses high-quality total population data with high coverage and validity.

The self-reported smoking habits during pregnancy in our data have been shown to be reliable and well covered in the Finnish Medical Birth Register.

- Socioeconomic status was defined based on maternal occupation, because no information was available on education and individual income.

\section{INTRODUCTION}

Finland has a long history to pursue progressive tobacco policies, and the first Tobacco Control Act was introduced in $1976 .{ }^{1}$ In order to achieve the goals in the Tobacco Control Act, an action plan has been introduced. The Action Plan vision is to achieve smoke-free Finland in a way that the smoking rate would be less than $2 \%$ in $2040 .{ }^{1}$ Raising taxes and prices, restricting access to tobacco products and information campaigns are some of the measures to promote the objectives of the Action Plan. ${ }^{1}$ As a result, smoking rates in the Finnish population are decreasing and the objective of making Finland smoke-free could be reached by the year $2030 .^{2}$ However, smoking during the pregnancy is still prevalent in Finland. ${ }^{3}$

Smoking during the pregnancy, as a modifiable maternal risk factor, has been reported to increase the risk of numerous adverse maternal and neonatal outcomes, including placenta previa, placental abruption, preterm birth, low birth weight, small for gestational age, neonatal intensive care admission, birth defects and sudden infant death syndrome..$^{4-8}$ The proportion of women who smoke during pregnancy varies across countries; in the USA 
$7.2 \%$ in 2016 , in Northwest Russia $18.9 \%$ of women and in Europe, ranging from $3.6 \%$ in Norway to $18.3 \%$ in Valencia in 2015. ${ }^{9-11}$ The share in Finland was $7.5 \%$ in $2015 .^{10}$ A number of individual-level characteristics have been associated with increased risk of smoking during the pregnancy, including maternal age, marital status, educational level, income, ethnicity and residential area. ${ }^{12-15}$

In addition, studies have documented that women with low socioeconomic status were more susceptible to adverse pregnancy outcomes. ${ }^{1617}$ In such studies, smoking during pregnancy was the most important extraneous factor that was related to the higher risks of adverse pregnancy outcomes among low socioeconomic groups. ${ }^{76} 18$ Studies indicated that socioeconomic disparities in the risk of preterm birth have been observed to widen with increasing female age, in an interactive and cumulative way; women from low socioeconomic groups are more vulnerable to adverse effects of risk factors than women from high socioeconomic groups. ${ }^{19}$ Thus, the prevalence of maternal risk factors partly explained the increased adverse pregnancy outcomes among low socioeconomic groups. Mechanisms underlying this disproportionate disparity in pregnancy outcomes remain unclear. ${ }^{19}$

Studies have evaluated the trend and pattern of smoking during pregnancy, but evidence regarding the joint effects of maternal age and socioeconomic status on the risk of smoking during pregnancy is scarce. Thus, this study aimed to explore the association between maternal age and smoking during the second and third trimesters of pregnancy across socioeconomic groups, to evaluate how socioeconomic status modifies the association between maternal age and smoking, and to inform public health interventions policies by identifying highrisk women to minimise the number of mothers smoking during the pregnancy in Finland.

\section{METHODS}

\section{Data and study population}

In this register-based study, we used the data from the Finnish Medical Birth Register (MBR) and Statistics Finland, including the information of 932671 women giving birth from 2000 to 2015. In Finland, maternity care is publicly funded and all women have universal access to antenatal and other medical care. All live births and stillbirths with a birth weight of at least $500 \mathrm{~g}$ or with a gestational age of at least 22 weeks have been registered in MBR since 1987 and maintained by the Finnish Institute for Health and Welfare (THL).$^{20}$ The MBR includes individual-level information on maternal background, pregnancy and delivery characteristics of all births. The data are collected at hospitals and sent electronically to THL where it is reviewed. The data from MBR and Statistics Finland were linked by using explicit and unique personal identity code, which was removed from the data after the statistical authorities completed the data linkages.

\section{Variables and definitions}

The variable maternal age was considered as a categorical variable and divided into the following categories: $<19$ (teenage births), 20-24, 25-29, 30-34 and $\geq 35$ (birth among women with advanced age). The age category of 30-34 was considered as the reference group, because women in this category were least likely to smoke during pregnancy (based on cross-tabulations).

The socioeconomic status was defined by maternal occupation at the time of delivery (from MBR). Year-end data on occupational class were derived from the register of Statistics Finland. The categorisation of occupational classes was based on the socioeconomic classification of Statistics Finland, a widely used classification of social position. ${ }^{21}$ We focused on the following categories: selfemployed persons; upper-level employees (administrative, managerial, professional and related occupations); lower-level employees (administrative and clerical occupations); manual workers; students; long-term unemployed; socioeconomic status unknown. Socioeconomic status unknown included women without occupation. The upper-level employees were considered as a reference group, because women in this category were least likely to smoke during the pregnancy (based on cross-tabulations).

The information about smoking habits was collected and reviewed during antenatal visits. Smoking was a selfreported variable, divided into the following categories: non-smoking women, stopped smoking during the first trimester, women continuing to smoke after the first trimester and missing information. In this study, smoking status was considered as a dichotomous variable (yes or no). Non-smoking women and women who quit smoking during the first trimester were recorded as nonsmokers, and women continuing to smoke after the first trimester of pregnancy were categorised as the smoking group. Smoking had 2.6\% ( $\mathrm{n}=23968)$ missing data. We dropped women with missing information on smoking. ${ }^{22}$

We classified parity according to the total number of births. In our data, mother's marital status was categorised as married, cohabiting and single. We have divided the study period of 2000-2015 into four time periods (2000-2003, 2004-2007, 2008-2011 and 2012-2015) to evaluate changes of subgroup sizes and risks over time.

\section{Statistical analyses}

The statistical analyses were performed using SPSS V.25 and Stata V.15. $\mathrm{P}<0.05$ was considered statistically significant.

Characteristics of the study population were evaluated using the Pearson $\chi^{2}$ test and reported as number and percentage; to examine whether the distribution of cases of one categorical variable varies across categories of maternal age.

We explored the association between maternal age and smoking during the second and third trimesters of pregnancy using multivariate logistic models. Socioeconomic status (maternal occupation and education), marital status and parity were hypothesised to be associated 
with both maternal age and smoking. To control for the confounding effect of maternal occupation, education (operationalised in the analysis using occupational status as a proxy for education) and parity, we performed separate multivariate logistic models for each socioeconomic group among nulliparous and multiparous women. We further adjusted the association between maternal age and smoking by including marital status to the logistic models. We represented our assumptions regarding the association between maternal age, smoking and other study variables using a Directed Acyclic Graph (see online supplementary file).

For the second objective of the study, we conducted a series of multivariate analyses. We first evaluated the crude effect of maternal age on smoking during the second and third trimesters of pregnancy. Model 1 adjusted for parity and model 2 adjusted for socioeconomic status, parity and marital status. We assessed interaction on the multiplicative scale (Statistical interaction) by entering the interaction term between maternal age and socioeconomic status in the final model. To aid the final model interpretation, we calculated marginal estimates and predicted probabilities based on logistic regression coefficients from the full model. We further assessed the interaction on the additive scale (biological interaction) by calculating the relative excess risk due to interaction (RERI) ${ }^{23}$

It is recommended to evaluate and present measures of interaction on both additive and multiplicative scales. ${ }^{24}$ However, the results of interaction can be inconsistent depending on the scale is used to assess the interaction. ${ }^{24}{ }^{25}$ In this study, the motivation for interaction analyses was to identify high-risk women who could benefit the most from the intervention. Because of this reason, the interpretation of effect modification was based on the results of interaction on the additive scale. Evaluation of additive interaction has been recognised to be relevant and crucial for life course theories and public health purposes. ${ }^{2425}$

In this study, the ORs and adjusted ORs (aORs) were used as a proxy for prevalence ratios.

\section{Patient and public involvement}

Patients and the public were not involved in any aspect of this study.

\section{RESULTS}

\section{Characteristics of the study population}

The study population covered 932671 women who gave birth in Finland from 2000 to 2015, among whom 82.5\% (769 036) were non-smokers, $4.5 \%$ (41 984) stopped smoking during the first trimester and 10.5\% (97 683) smoked after the first trimester. The proportion of women who smoked during the second and third trimesters of pregnancy decreased across all age groups from 2000 to 2015 (See online supplementary table S1).

The minimum value for the variable age was 13 years and the maximum value was 55 years old with the median age of 30 years. The age variable was not normally distributed. The majority of births occurred among women aged 30-34, with only $2.5 \%$ of births attributed to teenage mothers (table 1). Teenage mothers were more likely to be manual workers, long-term unemployed, self-employed and with unknown socioeconomic status, while advanced maternal age women were more likely to belong to the categories of upper-level and lower-level employees. Teenage mothers were more likely to be single, nulliparous and smokers than other age groups. Furthermore, with increasing maternal age in our study population, women had a relatively stable partnership and non-smoking lifestyle (table 1). The absolute number of women who smoked during the second and third trimesters of pregnancy by maternal age and socioeconomic status were summarised in the supplementary file. The largest number of women who smoked were women in manual occupations aged 20-24 years (8646 women) and 25-29 years (7556 women) as well as students 25-29 years (5140 women) (see online supplementary table S2).

\section{Relationship between maternal age and smoking status by parity and socioeconomic status}

The relationship between maternal age and smoking for nulliparous and multiparous women were stratified by socioeconomic groups (table 2). The association between maternal age and smoking was strongest for teenage mothers across all socioeconomic groups. The association became weaker with increasing maternal age except for nulliparous women in manual occupations, nulliparous students and nulliparous with unknown socioeconomic status (table 2). Declines in smoking have been steeper among nulliparous women aged 25-29 years than their multiparous counterparts (figure 1). As figure 1 depicts, socioeconomic disparities in smoking prevalence across reproductive age exist for both nulliparous and multiparous women. However, the socioeconomic differences were larger for multiparous women than their nulliparous counterparts.

The association between maternal age, socioeconomic status and smoking

The crude ORs identified strong associations between maternal age and smoking during the second and third trimesters of pregnancy across all maternal age groups (table 3). In comparison to women aged 30-34 years old, teenage mothers were almost eight times more likely to smoke during the second and third trimesters of pregnancy (OR 7.91, 95\% CI 7.67 to 8.16). The ORs for the association between teenage mothers and women in their 20s with smoking become stronger from 2000 to 2011 (see online supplementary table S3).

In model 1, controlling for parity strengthened the magnitude of the association between maternal age and smoking during the second and third trimesters for teenage mothers, women aged 20-24 years and women aged 25-29 years. In model 2, marital status and socioeconomic status were added. Women in manual occupations 
Table 1 Characteristics of the study population stratified according to the maternal age, from 2000 to 2015 in Finland Maternal age (years)

\begin{tabular}{|c|c|c|c|c|c|}
\hline Total $(\mathrm{n}, \%)^{\star}$ & $\begin{array}{l}\leq 19 \\
23028(2.5) \ddagger\end{array}$ & $\begin{array}{c}20-24 \\
146370(15.7)\end{array}$ & $\begin{array}{c}25-29 \\
292388(31.3)\end{array}$ & $\begin{array}{c}30-34 \\
292624(31.4)\end{array}$ & $\begin{array}{rl} & \geq 35 \\
178 & 261(19.1)\end{array}$ \\
\hline \multicolumn{6}{|l|}{ Characteristic $†$} \\
\hline \multicolumn{6}{|l|}{ Socioeconomic status ( $\mathrm{n}, \%)$} \\
\hline Self-employed persons & $938(4.8)$ & $5358(4.3)$ & $6806(2.7)$ & $5300(2.1)$ & $5345(3.5)$ \\
\hline Upper-level employees & $1019(5.2)$ & $7162(5.7)$ & 20389 (8.0) & $32333(12.7)$ & 30662 (19.9) \\
\hline Lower-level employees & $2979(15.3)$ & $22728(18.2)$ & $57650(22.7)$ & $71297(27.9)$ & 52239 (33.9) \\
\hline Manual workers & $6687(34.3)$ & $39395(31.5)$ & $60681(23.9)$ & $48574(19.0)$ & 26785 (17.4) \\
\hline Students & 3200 (16.4) & $28265(22.6)$ & $73010(28.8)$ & $64207(25.1)$ & 17454 (11.3) \\
\hline Long-term unemployed & $1924(9.9)$ & $8528(6.8)$ & $13517(5.3)$ & $13008(5.1)$ & $7698(5.0)$ \\
\hline $\begin{array}{l}\text { Socioeconomic status } \\
\text { unknown }\end{array}$ & 2765 (14.2) & $13454(10.8)$ & $21418(8.4)$ & $20640(8.1)$ & 13705 (8.9) \\
\hline \multicolumn{6}{|l|}{ Marital status (n,\%) } \\
\hline $\begin{array}{l}\text { Married or registered } \\
\text { partnership }\end{array}$ & $3806(16.8)$ & $56233(38.8)$ & $171376(59.0)$ & $195889(67.3)$ & $117653(66.4)$ \\
\hline Single & $18681(82.2)$ & $87152(60.2)$ & $117339(40.4)$ & $93666(32.2)$ & $58726(33.1)$ \\
\hline Missing & $234(1.0)$ & $1387(1.8)$ & $1726(0.6)$ & $1419(0.5)$ & $863(0.5)$ \\
\hline \multicolumn{6}{|l|}{ Parity (n, \%) } \\
\hline Nulliparous & $17175(74.6)$ & $71251(48.7)$ & $110097(37.7$ & $72913(24.9)$ & $23172(16.0)$ \\
\hline Multiparous & $5838(25.4)$ & $75012(51.3)$ & $182032(62.3)$ & $219513(75.1)$ & $121449(84.0)$ \\
\hline \multicolumn{6}{|l|}{ Smoking status (n, \%) } \\
\hline Non-smoker & $11473(49.8)$ & $101500(69.3)$ & 243789 (83.4) & $256171(87.5)$ & $126889(87.7)$ \\
\hline Quit during the first trimester & $2487(10.8)$ & $11841(8.1)$ & $13960(4.8)$ & $9371(3.2)$ & $3613(2.5)$ \\
\hline Smoker§ & $8380(36.4)$ & $29181(19.9)$ & $27487(9.4)$ & $19724(6.7)$ & $10292(7.1)$ \\
\hline
\end{tabular}

${ }^{*}$ Row percentages.

†Column percentages.

¥Values are number and percentage.

$\S$ Smoker refers to those who did not quit smoking during the first trimester. All maternal age differences were statistically significant at $\mathrm{p}<0.001$.

(aOR $3.39,95 \%$ CI 3.25 to 3.52 ) and long-term unemployed women (aOR 4.49, 95\% CI 4.30 to 4.68 ) were more than three and four times more likely to smoke than upper-level employees. The strength of the association for smoking across maternal age groups substantially attenuated, although the pattern remained the same. The aORs of smoking were higher for single (OR 2.98, 95\% CI 2.93 to 3.03 ) and multiparous (OR $1.84,95 \%$ CI 1.81 to 1.88 ) mothers than married and nulliparous women. In the final logistic regression model, the observed ORs for the joint effect of maternal age and socioeconomic status were significantly larger than what would be expected under the null hypothesis for unemployed women and women in manual occupations aged 35 years or older (table 3 ). Figure 2 provides predicted probabilities based on logistic regression coefficients from the full model (model 3).

Interactions on the additive scale between maternal age and socioeconomic status

We further assessed the interaction on the additive scale by calculating the RERI and the $95 \%$ CI for RERI (table 4 ).
We found that the joint effects of maternal age below 20 years, 20-24 years and socioeconomic status were larger than the sum of the individual effects of maternal age or socioeconomic status, except for women in the category of self-employed. Furthermore, we found a significant interaction on the additive scale between mothers aged 25-29 years and long-term unemployed women (RERI $2.26,95 \%$ CI 1.67 to 2.85$)$.

\section{DISCUSSION}

\section{Statement of principal findings}

The results obtained in our study showed that the prevalence of smoking during the second and third trimesters of pregnancy was greater among teenage mothers. Single mothers and multiparous women were more likely to smoke than married and nulliparous women. In our population, smoking during the second and third trimesters of pregnancy was less common among managerial occupations (upper-level employees), whereas long-term 
Table 2 Adjusted ORs for the association between maternal age and smoking during the second and third trimesters of pregnancy across socioeconomic groups among nulliparous and multiparous women, from 2000 to 2015 in Finland

\begin{tabular}{llllll}
\hline $\begin{array}{l}\text { Socioeconomic status } \\
\text { (SES) }\end{array}$ & $\begin{array}{l}\text { Maternal age } \\
\text { (years) }\end{array}$ & & & & \\
\hline & $\leq 19$ & $20-24$ & $25-29$ & $30-34$ & $\geq 35$ \\
\hline Nulliparous & & & & & \\
Self-employed persons & $7.77(7.41-8.14)^{*}$ & $3.40(3.27-3.54)$ & $1.29(1.23-1.34)$ & 1.00 (ref) & $1.19(1.12-1.26)$ \\
\hline Upper-level employees & $8.68(8.28-9.10)$ & $3.79(3.65-3.95)$ & $1.41(1.35-1.47)$ & 1.00 (ref) & $0.97(0.91-1.02)$ \\
\hline Lower-level employees & $6.55(6.28-6.82)$ & $2.94(2.85-3.04)$ & $1.20(1.16-1.24)$ & 1.00 (ref) & $1.10(1.06-1.15)$ \\
\hline Manual worker & $5.31(5.11-5.52)$ & $2.55(2.47-2.62)$ & $1.16(1.12-1.19)$ & 1.00 (ref) & $1.27(1.22-1.32)$ \\
\hline Students & $7.45(7.14-7.78)$ & $2.96(2.86-3.07)$ & $1.23(1.18-1.27)$ & 1.00 (ref) & $1.43(1.38-1.48)$ \\
\hline Long-term unemployed & $6.41(6.13-6.69)$ & $2.85(2.78-2.92)$ & $1.46(1.43-1.49)$ & 1.00 (ref) & $1.19(1.13-1.26)$ \\
\hline SES unknown & $5.75(5.51-6.00)$ & $2.66(2.57-2.75)$ & $1.15(1.11-1.19)$ & 1.00 (ref) & $1.31(1.26-1.38)$ \\
\hline Multiparous & & & & & \\
\hline Self-employed persons & $5.25(4.98-5.54)$ & $2.77(2.71-2.84)$ & $1.45(1.42-1.48)$ & 1.00 (ref) & $0.99(0.96-1.01)$ \\
\hline Upper-level employees & $5.30(5.03-5.59)$ & $2.81(2.74-2.87)$ & $1.44(1.41-1.48)$ & 1.00 (ref) & $0.99(0.96-1.01)$ \\
\hline Lower-level employees & $5.12(4.88-5.37)$ & $2.74(2.68-2.80)$ & $1.41(1.38-1.44)$ & 1.00 (ref) & $1.00(0.98-1.03)$ \\
\hline Manual workers & $4.80(4.60-5.01)$ & $2.66(2.60-2.70)$ & $1.42(1.39-1.45)$ & 1.00 (ref) & $1.00(0.97-1.02)$ \\
\hline Students & $5.26(5.01-5.52)$ & $2.77(2.71-2.83)$ & $1.40(1.37-1.43)$ & 1.00 (ref) & $1.04(1.01-1.07)$ \\
\hline Long-term unemployed & $5.40(5.13-5.69)$ & $2.83(2.76-2.90)$ & $1.46(1.42-1.49)$ & 1.00 (ref) & $0.99(0.96-1.01)$ \\
\hline SES unknown & $5.37(5.11-5.64)$ & $2.81(2.74-2.87)$ & $1.45(1.42-1.48)$ & 1.00 (ref) & $0.99(0.97-1.02)$ \\
\hline
\end{tabular}

For the association between maternal age and smoking across socioeconomic groups, women aged 30-34 years, used as the reference group (ref).

${ }^{*}$ Adjusted OR, 95\% Cl (adjusted by marital status).
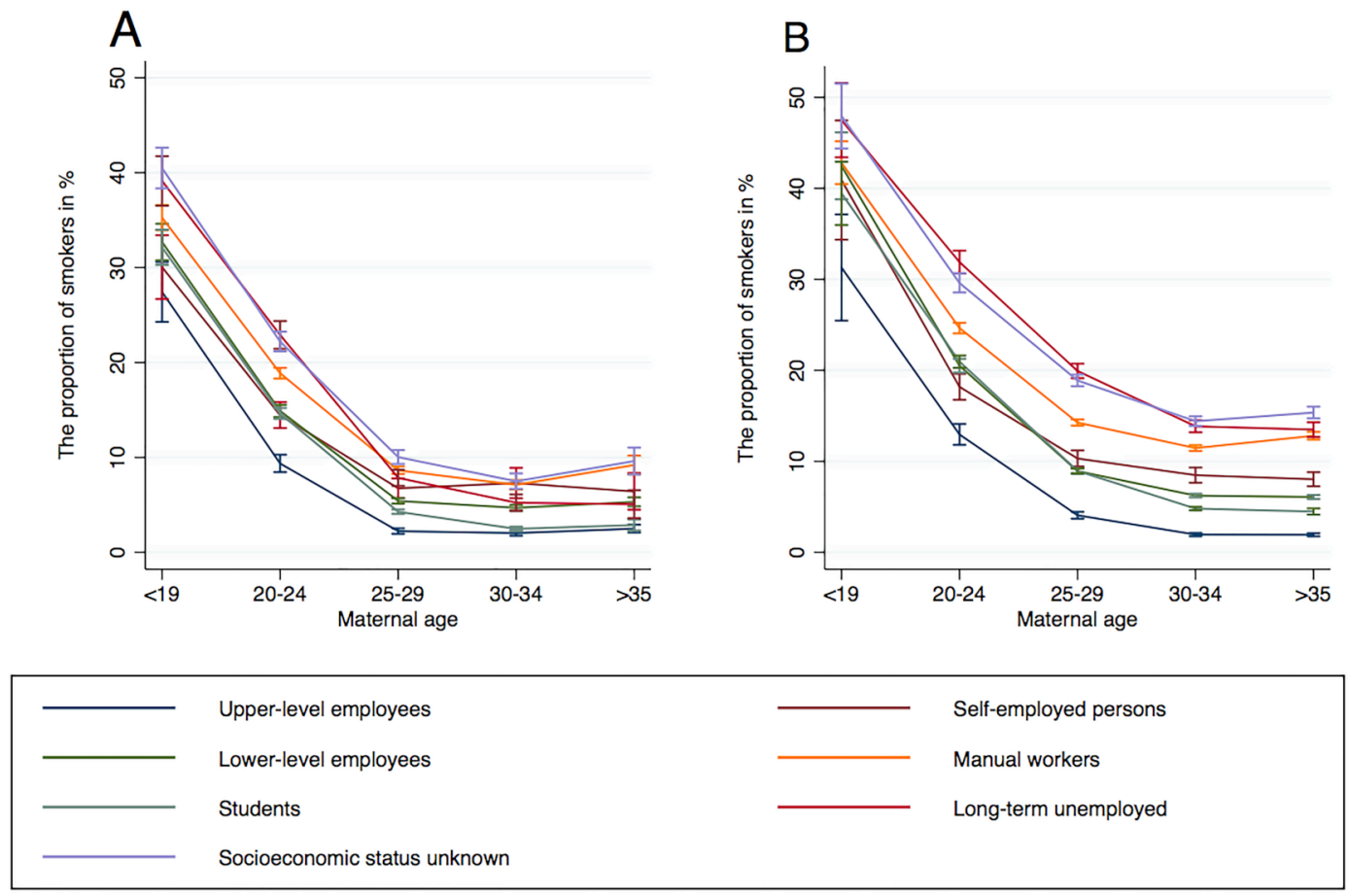

Figure 1 Relationship between maternal age and smoking during the second and third trimesters of pregnancy by socioeconomic status among nulliparous (A) and multiparous women (B), from 2000 to 2015 in Finland. Error bars indicate 95\% Cls. 
Table 3 ORs and adjusted ORs (aORs) for the association between maternal age, socioeconomic status (SES) and smoking during the second and third trimesters of pregnancy, from 2000 to 2015 in Finland

\begin{tabular}{|c|c|c|c|c|}
\hline Outcome & Crude & Model 1 & Model 2 & $\begin{array}{l}\text { Model } 3 \text { (main } \\
\text { effects+interactions) }\end{array}$ \\
\hline & OR $(95 \% \mathrm{Cl})$ & aOR $(95 \% \mathrm{Cl})$ & aOR $(95 \% \mathrm{Cl})$ & aOR $(95 \% \mathrm{Cl})$ \\
\hline \multicolumn{5}{|l|}{ Maternal age } \\
\hline$\leq 19$ & 7.91 (7.67 to 8.16$)$ & 10.56 (10.23 to 10.90$)$ & 6.02 (5.81 to 6.24$)$ & 14.79 (12.60 to 17.37$)$ \\
\hline $20-24$ & 3.44 (3.37 to 3.51$)$ & 3.92 (3.85 to 4.00$)$ & 2.77 (2.71 to 2.84 ) & 4.99 (4.47 to 5.56$)$ \\
\hline $25-29$ & $1.43(1.40$ to 1.46$)$ & $1.53(1.50$ to 1.56$)$ & 1.35 (1.32 to 1.38$)$ & 1.64 (1.47 to 1.84$)$ \\
\hline $30-34$ & 1.00 (ref) & 1.00 (ref) & 1.00 (ref) & 1.00 (ref) \\
\hline$\geq 35$ & $1.08(1.05$ to 1.10$)$ & $1.03(1.00$ to 1.05$)$ & 1.03 (1.01 to 1.06$)$ & 0.91 (0.81 to 1.02$)$ \\
\hline \multicolumn{5}{|l|}{ Parity } \\
\hline Nulliparous & & 1.00 (ref) & 1.00 (ref) & 1.00 (ref) \\
\hline Multiparous & & $1.73(1.70$ to 1.75$)$ & 1.84 (1.81 to 1.88$)$ & $1.84(1.80$ to 1.87$)$ \\
\hline \multicolumn{5}{|l|}{ SES } \\
\hline Self-employed persons & & & 2.54 (2.40 to 2.69$)$ & 3.77 (3.32 to 4.28$)$ \\
\hline Lower-level employees & & & 2.17 (2.09 to 2.26$)$ & 2.66 (2.44 to 2.90$)$ \\
\hline Upper-level employees & & & 1.00 (ref) & 1.00 (ref) \\
\hline Manual workers & & & 3.39 (3.25 to 3.52$)$ & $4.63(4.26$ to 5.04$)$ \\
\hline Students & & & 1.97 (1.89 to 2.05 ) & 1.85 (1.69 to 2.02$)$ \\
\hline Long-term unemployed & & & 4.49 (4.30 to 4.68$)$ & 5.94 (5.43 to 6.49$)$ \\
\hline SES unknown & & & 4.35 (4.16 to 4.55$)$ & 5.46 (4.96 to 6.01$)$ \\
\hline \multicolumn{5}{|l|}{ Marital Status } \\
\hline $\begin{array}{l}\text { Married or registered } \\
\text { partnership }\end{array}$ & & & 1.00 (ref) & 1.00 (ref) \\
\hline Single & & & 2.98 (2.93 to 3.03 ) & 2.96 (2.92 to 3.01$)$ \\
\hline \multicolumn{5}{|l|}{ Interaction age ${ }^{\star}$ SES } \\
\hline$<19^{*}$ self-employed persons & & & & 0.34 (0.27 to 0.44$)$ \\
\hline$\leq 19 *$ lower-level employees & & & & 0.48 (0.40 to 0.58$)$ \\
\hline$\leq 19^{*}$ manual workers & & & & $0.31(0.26$ to 0.36$)$ \\
\hline$\leq 19^{*}$ students & & & & 0.70 (0.57 to 0.84$)$ \\
\hline$\leq 19 *$ long-term unemployed & & & & $0.30(0.25$ to 0.36$)$ \\
\hline$\leq 19 *$ SES unknown & & & & 0.32 (0.26 to 0.39$)$ \\
\hline $20-24^{*}$ self-employed persons & & & & 0.39 (0.33 to 0.47$)$ \\
\hline $20-24^{*}$ lower-level employees & & & & 0.59 (0.53 to 0.67$)$ \\
\hline $20-24^{*}$ manual workers & & & & 0.43 (0.39 to 0.49$)$ \\
\hline $20-24^{*}$ students & & & & 0.89 (0.79 to 1.00$)$ \\
\hline $20-24 *$ long-term unemployed & & & & 0.44 (0.39 to 0.50$)$ \\
\hline 20-24*SES unknown & & & & 0.51 ( 0.45 to 0.58$)$ \\
\hline $25-29^{*}$ self-employed persons & & & & 0.66 (0.55 to 0.78$)$ \\
\hline 25-29*lower-level employees & & & & 0.78 (0.69 to 0.88$)$ \\
\hline $25-29^{*}$ manual workers & & & & 0.72 (0.64 to 0.81$)$ \\
\hline $25-29^{*}$ students & & & & 1.05 (0.93 to 1.19$)$ \\
\hline $25-29 *$ long-term unemployed & & & & 0.77 (0.68 to 0.87$)$ \\
\hline $25-29 *$ SES unknown & & & & 0.85 (0.74 to 0.97$)$ \\
\hline$\geq 35^{*}$ self-employed persons & & & & 0.99 (0.82 to 1.19$)$ \\
\hline$\geq 35^{\star}$ lower-level employees & & & & $1.02(0.90$ to 1.15$)$ \\
\hline$\geq 35^{\star}$ manual workers & & & & 1.24 (1.10 to 1.41$)$ \\
\hline$\geq 35^{*}$ students & & & & $1.05(0.91$ to 1.21$)$ \\
\hline
\end{tabular}


Table 3 Continued

\begin{tabular}{|c|c|c|c|c|}
\hline Outcome & Crude & Model 1 & Model 2 & $\begin{array}{l}\text { Model } 3 \text { (main } \\
\text { effects+interactions) }\end{array}$ \\
\hline$\geq 35^{\star}$ long-term unemployed & & & & 1.19 (1.04 to 1.35$)$ \\
\hline Intercept & $0.072(0.071-0.073)$ & $0.046(0.045-0.047)$ & $0.010(0.010-0.011)$ & 0.009 (0.008-0.009) \\
\hline
\end{tabular}

Model 1 is adjusted by parity; model 2 is adjusted by parity, marital status and SES; model 3 is adjusted by all variables included in model 2 and interaction term on the multiplicative scale between maternal age and SES.

unemployed women and women in manual occupations were three to four times as likely as those in upper-level employees to smoke. Thus, both maternal age and socioeconomic status have independent effects on smoking. In addition to the above independent mechanisms, the results suggested that the effect of maternal age on smoking also depends on maternal socioeconomic status. Maternal age (below 20 years and from 20 to 24 years) and low socioeconomic status constitute synergistic interactions on the additive scale, resulting in stronger effects on smoking.

\section{Relation to other studies}

These findings are consistent with previous studies that have shown increased risks of smoking during pregnancy for young, single and multiparous mothers as well as women with low socioeconomic status. ${ }^{15}$ 26-28 However, no interaction between maternal age and socioeconomic status was reported in these studies. Interactions between maternal age and socioeconomic status have been investigated only on the multiplicative scale for adverse pregnancy outcomes than maternal risk factors. ${ }^{29}$ The results of additive interactions indicated that young maternal age and low socioeconomic status interact synergistically resulting in stronger effects on the risk of smoking. Focusing only on the results of multiplicative interaction, however, could lead to the wrong conclusion that smoking during pregnancy should not be targeted as aggressively among younger women compared with women 35 years or older with low socioeconomic status. Our findings showed that the joint effect of age and socioeconomic status on smoking during the second and third trimesters of pregnancy was scale-dependent. ${ }^{25}$ Although the results of this population-based study are likely to be highly
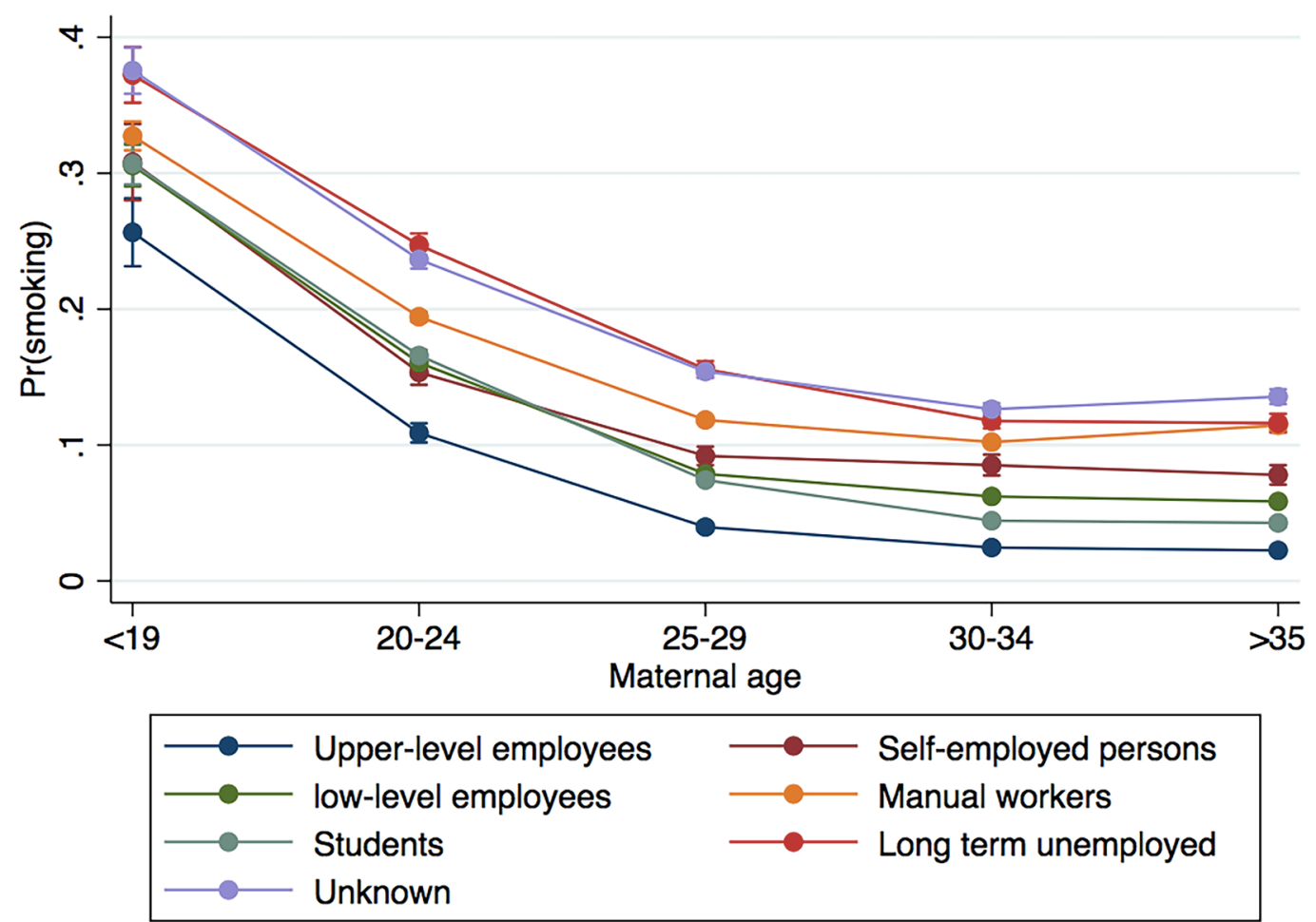

Figure 2 The probability of smoking during the second and third trimesters of pregnancy, predicted by age and socioeconomic groups. Maternal age 30-34, upper-level employee is the reference group. adjusted for parity and marital status. The interaction term is in the model. Error bars indicate $95 \% \mathrm{Cls.}$ 
statically significant, because of the large sample size and the number of interactions that have been tested, other studies in Finland have indicated that the contribution of low socioeconomic status to adverse perinatal outcomes was to a large extent related to smoking during pregnancy. ${ }^{7830}$ Our results were consistent with the results of these studies.

From a psychological point of view, young maternal age, as an age of instability, is an isolated risk factor for risky health behaviours and smoking during the pregnancy, mainly because of biological, social and psychological transitions during this period. ${ }^{31}$ From a sociological point of view, young mothers tended to have a higher likelihood of being single, having a spouse and friends who smoke and having less knowledge about the health risks of smoking. ${ }^{27} 3233$ These individual-level risk factors for smoking are imbedded with women's socioeconomic status. Poor socioeconomic situation, as an upstream social determinant, can contribute to unhealthy behaviours, maternal psychological stress and consequently higher risk of adverse pregnancy outcomes (downstream). ${ }^{34}$ Thus, a wide range of risk factors in low socioeconomic groups need to be addressed for public health intervention.

\section{Study strengths and limitations}

One of the strengths of this study is that the data were drawn from a comprehensive and reliable register-based database which represent the whole population of women in Finland. Large data increase the power of our study and the precision of the risk estimates. Furthermore, the information in MBR has been shown to have high coverage and validity. ${ }^{35}$ Another strength of the study is that the smoking habits of women were assessed at every prenatal care visit, which provides better reliability than collecting information at the time of delivery only.

One limitation of this study was that there is no individuallevel information on women educational level and income. In Finland, however, socioeconomic status, education and income are interrelated with occupation; women's educational level shapes future employment, income and women's position in society. For instance, managerial occupations in upper-level employee groups require higher university-level qualifications or manual occupations require few or no specific qualifications. Another limitation of the study was that the data on variable smoking were self-reported. Selfreported smoking habits may have underestimated the true prevalence of smoking, particularly women bellow the age of 30 years, nulliparous women, single mothers and women with low socioeconomic status are more likely to have underreported. ${ }^{35}$ Thus, the associations between these variables and smoking could be underestimated, depending on the extent to which smoking has been under-reported. Nonetheless, the information on the variable smoking has been previously validated. ${ }^{36}$ Furthermore, the results of ORs and aORs should be interpreted with caution. Since the prevalence of smokers was high in many subgroups, the ORs and aORs could overestimate the prevalence ratios, particularly the OR and adjusted aOR for the association between teenage mothers and smoking. ${ }^{38} 39$ 


\section{Implications for clinicians or policy-makers}

Despite the increased awareness about the potential adverse effects of smoking on pregnancy outcomes and advice of healthcare professionals about quitting smoking from the first visit of pregnancy, the rate of smoking in early pregnancy has remained relatively stable in Finland since the mid-1990s. ${ }^{28}$ At the same time, the prevalence of smoking during the pregnancy has decreased in the USA, Australia and all other Nordic countries. ${ }^{32}$ In addition, pregnant teenagers in Finland were more likely to smoke than other Nordic countries. ${ }^{32}$ Thus, interventions to address smoking have not been technically successful.

Among young women, especially those with low socioeconomic status and students, smoking prevention and intervention programmes could be integrated with other healthcare services or implemented through the preconception period, educational institutions and work sites. ${ }^{3} 1340$

Moreover, studies have shown that pregnancy and routine prenatal care with systematic and well-design health education are unique opportunities for evidence-based smoking cessation interventions. ${ }^{1428}$ However, the limited success in implementing smoking intervention programmes during the relatively short duration of pregnancy may be due to lack of sufficient prioritisation, and not because of lack of motivation in quitting smoking. ${ }^{40}$ Based on the results of the current study, policies should aim to improve a broad range of maternal risk factors especially among teenagers and low socioeconomic groups in order to prevent smoking during the pregnancy and improve birth outcomes. Pregnant women at a younger age with low socioeconomic status have a higher likelihood of being single or having an unwanted pregnancy. Therefore, single mothers are disproportionately affected by other risk factors which are associated with smoking and consequently adverse pregnancy outcomes. Improving social support of teenage mothers could decrease the effect of these stressors. ${ }^{42}{ }^{43}$ For multiparous women, especially those with low socioeconomic status, antismoking interventions are necessary to focus on changes in stage of behaviours by informing women about the adverse effect of smoking on pregnancy at the first stage, even if previous pregnancy had no adverse outcomes. ${ }^{445}$

Although the results of the current study indicated that teenage mothers with low socioeconomic status had elevated risks of smoking, at the same time, interventions need to be expanded to cover a larger number of women who smoked during the pregnancy. Thus, targeting high-risk women as well as women in manual occupations and students, as the largest number of women how smoked during pregnancy, should be seen as complementary to minimise the actual number of women who smoke during the pregnancy. ${ }^{46}$

In conclusion, smoking during the second and third trimesters of pregnancy was most common among teenage mothers across all socioeconomic groups. The association between maternal age and smoking differed by socioeconomic status for young mothers. This, in turn, implies that current public maternity care, which is offered to all women free of charge either fails to a large extent to recognise or target the high-risk groups or the high-risk groups are unresponsive to the current intervention programmes. Interventions should address a wider range of maternal risk factors among young mothers with low socioeconomic status and simultaneously target a broader number of women who smoke during pregnancy. Further research is needed to find optimal ways to target the high-risk groups as well as students to cut down the effects of preventable risks brought about by maternal smoking.

\section{Author affiliations}

${ }^{1}$ Department of Health Sciences, University of Helsinki Faculty of Medicine, Helsinki, Finland

${ }^{2}$ School of Health Care and Social Services, Tampere University of Applied Sciences, Tampere, Pirkanmaa, Finland

${ }^{3}$ Information Services Department, Finnish Institute for Health and Welfare, Helsinki, Uusimaa, Finland

${ }^{4}$ Department of Neurobiology, Care Sciences and Society, Division of Family Medicine and Primary Care, Karolinska Institute, Stockholm, Sweden

${ }^{5}$ Department of Obstetrics and Gynaecology, Helsinki University Central Hospital, Helsinki, Uusimaa, Finland

Acknowledgements We are grateful to the Finnish Institute of Health and Welfare (THL) for managing the data and facilitating access to the data.

Contributors ZR designed the study, conducted the statistical analysis and drafted the manuscript. SR designed the study, interpreted the results, revised the manuscript. MG interpreted the data, revised the manuscript. SH designed the study, interpreted the results, revised the manuscript. All authors reviewed the manuscript. All authors have read and approved the final version to be published.

Funding This work was supported by 0tto A. Malm Foundation.

Competing interests None declared.

Patient consent for publication Not required.

Ethics approval The ethical approval for this study was gained from the Finnish Institute of Health and Welfare (THL) (Permission number THL/876/5.05.00/2017), which is required by the national data protection legislation.

Provenance and peer review Not commissioned; externally peer reviewed.

Data availability statement Data may be obtained from a third party and are not publicly available. The Finnish register data have been given for this specific study, and the data cannot be shared without authorisation from the register keepers. More information on the authorisation application to researchers who meet the criteria for access to confidential data can be found at https://thl.fi/en/web/thlfi-en/ statistics/information-for-researchers/authorisation-application (THL) and https:// www.stat.fi/meta/tietosuoja/kayttolupa_en.html (Statistics Finland). No additional data are available.

Open access This is an open access article distributed in accordance with the Creative Commons Attribution Non Commercial (CC BY-NC 4.0) license, which permits others to distribute, remix, adapt, build upon this work non-commercially, and license their derivative works on different terms, provided the original work is properly cited, appropriate credit is given, any changes made indicated, and the use is non-commercial. See: http://creativecommons.org/licenses/by-nc/4.0/.

ORCID iD

Zahra Roustaei http://orcid.org/0000-0002-7337-640X

\section{REFERENCES}

1 Ministry of Social Affairs and Health. Roadmap to a tobacco- free Finland. action plan on tobacco control, 2014. Available: http:// julkaisut.valtioneuvosto.fi/bitstream/handle/10024/70305/ uRn_Isbn 978-952-00-3513-6.pdf [Accessed 18 Feb 2020].

2 National Institute for Health and Welfare. New era for tobacco control policy - proposals by the tobacco policy development working group of the tobacco-free Finland 2040 network, 2013. http://urn.fi/URN: ISBN:978-952-302-116-7

3 Lange S, Probst C, Rehm J, et al. National, regional, and global prevalence of smoking during pregnancy in the general population: 
a systematic review and meta-analysis. Lancet Glob Health 2018;6:e769-76.

4 Castles A, Adams EK, Melvin CL, et al. Effects of smoking during pregnancy. Am J Prev Med 1999;16:208-15.

5 Dietz PM, England LJ, Shapiro-Mendoza CK, et al. Infant morbidity and mortality attributable to prenatal smoking in the U.S. Am J Prev Med 2010;39:45-52.

6 Hackshaw A, Rodeck C, Boniface S. Maternal smoking in pregnancy and birth defects: a systematic review based on 173687 malformed cases and 11.7 million controls. Hum Reprod Update 2011;17:589-604.

7 Räisänen S, Gissler M, Sankilampi U, et al. Contribution of socioeconomic status to the risk of small for gestational age infants-a population-based study of 1,390,165 singleton live births in Finland. Int J Equity Health 2013;12:28.

8 Räisänen S, Sankilampi U, Gissler M, et al. Smoking cessation in the first trimester reduces most obstetric risks, but not the risks of major congenital anomalies and admission to neonatal care: a populationbased cohort study of 1,164,953 singleton pregnancies in Finland. $J$ Epidemiol Community Health 2014;68:159-64.

9 Drake P, Driscoll AK, Mathews TJ. Cigarette smoking during pregnancy: United States, 2016. NCHS Data Brief 2018;305:1-8.

10 Project E-P. European perinatal health report. 2015. Available: www. europeristat.com [Accessed 1 May 2020].

11 Kharkova OA, Krettek A, Grjibovski AM, et al. Prevalence of smoking before and during pregnancy and changes in this habit during pregnancy in northwest Russia: a Murmansk County birth registry study. Reprod Health 2016;13:18.

12 Dias-Damé JL, Cesar JA. Disparities in prevalence of smoking and smoking cessation during pregnancy: a population-based study. Biomed Res Int 2015;2015:1-8.

13 Ebrahim SH, Floyd RL, Merritt RK, et al. Trends in pregnancyrelated smoking rates in the United States, 1987-1996. JAMA 2000;283:361-6.

14 Jaakkola N, Jaakkola MS, Gissler M, et al. Smoking during pregnancy in Finland: determinants and trends, 1987-1997. Am J Public Health 2001;91:284-6.

15 Räisänen S, Kramer MR, Gissler M, et al. Smoking during pregnancy was up to $70 \%$ more common in the most deprived municipalities - a multilevel analysis of all singleton births during 2005-2010 in Finland. Prev Med 2014;67:6-11.

16 Gray R, Bonellie SR, Chalmers J, et al. Contribution of smoking during pregnancy to inequalities in stillbirth and infant death in Scotland 1994-2003: retrospective population based study using hospital maternity records. BMJ 2009;339:b3754.

17 Blumenshine P, Egerter S, Barclay CJ, et al. Socioeconomic disparities in adverse birth outcomes: a systematic review. Am J Prev Med 2010;39:263-72.

18 Gissler M, Meriläinen J, Vuori E, et al. Register based monitoring shows decreasing socioeconomic differences in finnish perinatal health. J Epidemiol Community Health 2003:57:433-9.

19 Behrman RE, Butler AS. Preterm birth: causes, consequences, and prevention. Washington, DC: The National Academies Press, 2007.

20 The Finnish Institute for Health and Welfare (THL). Medical birth register. 2019. Available: https://thl.fi/fi/web/thlfi-en/statistics/ information-on-statistics/register-descriptions/newborns [Accessed 1 Sep 2019].

21 Finland S. Classification of socioeconomic groups, 2017. Available: http://stat.fi.libproxy.helsinki.fi/meta/luokitukset/sosioekon asema/ 001-1989/koko_luokitus_en.html [Accessed 17 Mar 2019]

22 Greenland S, Finkle WD. A critical look at methods for handling missing covariates in epidemiologic regression analyses. Am J Epidemiol 1995;142:1255-64.

23 Knol MJ, van der Tweel I, Grobbee DE, et al. Estimating interaction on an additive scale between continuous determinants in a logistic regression model. Int J Epidemiol 2007;36:1111-8.

24 VanderWeele TJ, Knol MJ. A tutorial on interaction. Epidemiol Method 2014;3:33-72.
25 Mehta NK, Zheng H, Myrskylä M. How do age and major risk factors for mortality interact over the life-course? implications for health disparities research and public health policy. SSM Popul Health 2019;8:100438.

26 Al-Sahab B, Saqib M, Hauser G, et al. Prevalence of smoking during pregnancy and associated risk factors among Canadian women: a national survey. BMC Pregnancy Childbirth 2010;10:24.

27 Schneider S, Schütz J. Who smokes during pregnancy? A systematic literature review of population-based surveys conducted in developed countries between 1997 and 2006. Eur J Contracept Reprod Health Care 2008;13:138-47.

28 Rumrich IK, Vähäkangas K, Viluksela M, et al. Smoking during pregnancy in Finland - Trends in the MATEX cohort. Scand J Public Health 2019;47:890-8.

29 Dennis JA, Mollborn S. Young maternal age and low birth weight risk: an exploration of racial/ethnic disparities in the birth outcomes of mothers in the United States. Soc Sci J 2013;50:625-34.

30 Räisänen S, Gissler M, Kramer MR, et al. Influence of delivery characteristics and socioeconomic status on giving birth by caesarean section - a cross sectional study during 2000-2010 in Finland. BMC Pregnancy Childbirth 2014;14:120.

31 Sussman S, Arnett JJ. Emerging adulthood: developmental period facilitative of the addictions. Eval Health Prof 2014;37:147-55.

32 Ekblad M, Gissler M, Korkeila J, et al. Trends and risk groups for smoking during pregnancy in Finland and other Nordic countries. Eur $J$ Public Health 2014;24:544-51.

33 Reitan T, Callinan S. Changes in smoking rates among pregnant women and the general female population in Australia, Finland, Norway, and Sweden. Nicotine Tob Res 2017;19:282-9.

34 Kramer MS, Séguin L, Lydon J, et al. Socio-economic disparities in pregnancy outcome: why do the poor fare so poorly? Paediatr Perinat Epidemiol 2000;14:194-210.

35 Gissler M, Shelley J. Quality of data on subsequent events in a routine medical birth register. Med Inform Internet Med 2002;27:33-8.

36 Männistö T, Bloigu A, Heino A, et al. Changes in objectively measured smoking in pregnancy by time and legislative changes in Finland: a retrospective cohort study. BMJ Open 2016;6:e013296.

37 Tikkanen M, Surcel H-M, Bloigu A, et al. Self-reported smoking habits and serum cotinine levels in women with placental abruption. Acta Obstet Gynecol Scand 2010;89:1538-44.

38 Barros AJD, Hirakata VN. Alternatives for logistic regression in cross-sectional studies: an empirical comparison of models that directly estimate the prevalence ratio. BMC Med Res Methodol 2003;3:21.

39 Janani L, Mansournia MA, Nourijeylani K, et al. Statistical issues in estimation of adjusted risk ratio in prospective studies. Arch Iran Med 2015;18:713-9.

40 Lantz PM. Smoking on the rise among young adults: implications for research and policy. Tob Control 2003;12:60i-70.

41 Owen L, McNeill A, Callum C. Trends in smoking during pregnancy in England, 1992-7: quota sampling surveys. BMJ 1998;317:728-30.

42 Hennrikus D, Pirie P, Hellerstedt W, et al. Increasing support for smoking cessation during pregnancy and postpartum: results of a randomized controlled pilot study. Prev Med 2010;50:134-7.

43 Raatikainen K, Heiskanen N, Heinonen S. Marriage still protects pregnancy. BJOG 2005;112:1411-6.

44 ACOG (American College of Obstetricians and Gynecologists). Motivational interviewing: a tool for behavior change. ACOG committee opinion no. 423. Obstet Gynecol 2009;113:243-6.

45 Kendrick JS, Zahniser SC, Miller N, et al. Integrating smoking cessation into routine public prenatal care: the smoking cessation in pregnancy project. Am J Public Health 1995;85:217-22.

46 Mackenbach JP, Lingsma HF, van Ravesteyn NT, et al. The population and high-risk approaches to prevention: quantitative estimates of their contribution to population health in the Netherlands, 1970-2010. Eur J Public Health 2013;23:909-15. 